Pesq. Vet. Bras. 25(3):143-149, jul./set. 2005

\title{
Sobre um surto de envenenamento por derivado cumarínico em bovinos ${ }^{1}$
}

\author{
Marilene F. Brito ${ }^{2}$, Josilene N. Seixas ${ }^{3}$, Flávia F. Jabour ${ }^{3}$, Gisele B. Andrade ${ }^{2}$, \\ Bernardo R.M. Cunha ${ }^{3}$, Ticiana N. França ${ }^{4}$ e Paulo V. Peixoto ${ }^{5}$
}

\begin{abstract}
Brito M.F., Seixas J.N., Jabour F.F., Andrade G.B., Cunha B.R.M., França T.N. \& Peixoto P.V. 2005. [About an outbreak of cumarin poisoning in cattle.] Sobre um surto de envenenamento por derivado cumarínico em bovinos. Pesquisa Veterinária Brasileira 25(3):143-149. Depto Epidemiologia e Saúde Pública, Instituto de Veterinária, UFRRJ, Seropédica, RJ 23890-000, Brazil.E-mail:marilene@ufrrj.br

An outbreak of cumarin poisoning which occurred in feedlot cattle in the county of Seropédica, Rio de Janeiro, is described. Three from 43 animal died. The main manifestations included bloody diarrhea, apathy, anorexia, sialorrhoe, incoordenation and dyspnoe. At post-mortem examinations there were mainly hemorrhages of varies forms and intensity in several organs, which also were seen at histopathological examination. Analysis for cumarin derivates of rumen, reticulum, omasum and abomasum contents, of liver and kidney samples, as well as of food collected from the trough, resulted positive for cumarin compounds which included warfarin, bromadiolone and brodifacoum. Feeding experiments with food stored at the property resulted negative. An intentional or accidental act could not be excluded. Animals that did not feed from the same trough did not get sick.
\end{abstract}

INDEX TERMS: Cumarin poisoning, cattle.

RESUMO.- Relata-se um surto de envenenamento por derivado cumarínico em bovinos confinados, ocorrido no município de Seropédica, Rio de Janeiro, no qual morreram duas vacas e um touro, de um total de 43 animais. Entre as principais manifestações clínicas observaram-se apatia, anorexia, sialorréia, diarréia sanguinolenta, incoordenação e dificuldade respiratória. À necropsia observaram-se principalmente hemorragias de intensidade e formas diversas, em vários órgãos. O exame histopatológico não evidenciou alterações, além de hemorragias. A pesquisa toxicológica em conteúdos de rúmen, retículo, omaso e abomaso, em amostras de fígado e rim, bem como da cevada coletada no cocho, resultou positiva para o grupo de derivados cumarínicos que inclui warfarina, bromadiolone e

\footnotetext{
${ }^{1}$ Recebido em 10 de agosto de 2004.

Aceito para publicação em 22 de setembro de 2004.

${ }^{2}$ Disciplina de Anatomia Patológica, Depto Epidemiologia e Saúde Pública, Instituto de Veterinária, Universidade Federal Rural do Rio de Janeiro (UFRRJ), Seropédica, RJ 23890-000. E-mail: marilene@ufrrj.br

${ }^{3}$ Mestrando do Curso de Medicina Veterinária da UFRRJ.

${ }^{4}$ Disciplina de Anatomia Patológica, Universidade Estácio de Sá, Estrada Boca do Mato 850, Vargem Pequena, RJ 22783-320.

5 Depto Nutrição Animal e Pastagem, Instituto de Zootecnia, UFRRJ, Seropédica, RJ 23890-000.
}

bromadifacoum. Não se pode excluir uma ação intencional ou acidental, visto que os animais que não estavam se alimentando no mesmo cocho, não adoeceram.

TERMOS DE INDEXAÇÃO: Cumarínicos, envenenamento, bovino.

\section{INTRODUÇÃO}

A ingestão de rodenticidas anticoagulantes é a causa mais freqüente de intoxicação em cães, e ocasional em gatos (Radostits et al. 2000, Lutze et al. 2003, Cope 2004). Embora ofereça elevado risco a todos os mamíferos e pássaros (Aiello 1998), em bovinos há poucos relatos de intoxicação por warfarina (Pugh 1968, Ashworth 1973, Gripper 1973, Fox \& Rebhun 1993, Radostits et al. 2000). O envenenamento pode ocorrer através da ingestão de iscas ou pelo consumo de roedores envenenados, de alimentos contaminados ou pelo uso criminoso destas substâncias. $\mathrm{O}$ intervalo entre a ingestão e a manifestação, bem como a severidade do quadro, varia com a toxidez, com a quantidade ingerida e com o estoque corporal e a bioatividade da vitamina $\mathrm{K}$ no animal (Lehninger 1984). Há grande variação na dose letal de acordo com a espécie envolvida e até entre indivíduos da mesma espécie, sendo os gatos mais sensíveis e as aves, mais resistentes. Alguns animais intoxicados por derivados cumarínicos podem morrer subitamente sem sinais prévios e, à necropsia, apresen- 
tar hemorragias disseminadas e fatais que se desenvolvem a partir de capilares e pequenos vasos sanguíneos após traumatismos leves (Humphreys 1988, Radostits et al. 2000), ferimentos acidentais ou cirúrgicos, contusões e lesões pouco importantes (Radostits et al. 2000). Quando ocorrem em órgãos vitais, saco pericárdico ou sob as meninges, as hemorragias podem ser rapidamente fatais (Valli \& Parry 1993). Nos casos com evolução subaguda, hemorragias subcutâneas, grandes hematomas e laminite aguda podem se desenvolver como conseqüência da diátese hemorrágica após traumatismos e punções venosas (Radostits et al. 2000). As hemorragias musculares ao longo das fáscias, principalmente próximas a proeminências ósseas dos membros e costelas, articulares e cavitárias são comuns (Humphreys 1988, Valli \& Parry 1993).

Em bovinos, diversas doenças decorrentes do aumento da fragilidade vascular, de desordens plaquetárias e/ou de alterações no mecanismo da coagulação se manifestam pelo aparecimento de petéquias e equimoses ou por sangramento excessivo (Cotran et al. 2000, Radostits et al. 2000). A intoxicação por antagonistas da vitamina $\mathrm{K}$, a coagulopatia adquirida mais conhecida, resulta na produção alterada de protrombina e dos fatores de coagulação (VII, IX, X), e tem sido observada em casos de ingestão de cumarinas, presentes em algumas plantas e em certos rodenticidas. Coagulopatia semelhante pode ser induzida pela ingestão de sulfaquinoxalina, a qual é utilizada como coccidiostático em animais de produção, aves domésticas ou como ingrediente adicional nos rodenticidas (Valli \& Parry 1993, Lutze et al. 2003).

Mesmo fenadas ou ensiladas algumas plantas como Melilotus alba (trevo-doce), M. altissima, M. indica, M. officinalis, Anthoxanthum odoratum, Lespedeza stipulacea e Ferula communis contêm cumarinas, as quais podem transformar-se em dicumarol tóxico (dicumarina ou dihidroxicumarina) pela ação de fungos (Puschner et al. 1998, Runciman 2002), especialmente os dos gêneros Aspergillus (Puschner et al. 1998), Penicillium e Mucor (Radostits et al. 2000). A armazenagem incorreta propicia a formação de substratos necessários ao crescimento fúngico e à produção de dicumarol tóxico, encontrado em maiores concentrações na porção externa de fardos grandes. A intoxicação em bovinos ocorre quando há ingestão de quantidade igual ou superior a $20 \mathrm{mg}$ de dicumarina/ $\mathrm{kg}$ de trevo-doce fenado (Cotran et al. 2000). Após a descoberta do dicumarol, vários derivados de cumarina estão sendo sintetizados com o objetivo de reduzir temporariamente a coagulabilidade sanguínea ou de produzir rodenticidas como a warfarina, fumarina, pindone, diphacinone, bromadifacoum, coumatetralyl, coumachlor, difenacoum, menaphthone e bromadiolone (Humphreys 1988, Valli \& Parry 1993, Stirling 1995, Radostits et al. 2000).

A ingestão de dicumarol em pequenas doses interfere com a produção de protrombina no fígado, em consequiência, há aumento no tempo de sangramento (Humphreys 1988), sem alteração na concentração de fibrinogênio ou interferência no número ou na função das plaquetas (Valli \& Parry 1993, Lutze 2003), que constituem achados laboratoriais significativos para o diagnóstico de intoxicação por derivados cumarínicos. Nos casos de intoxicação por trevo-doce, além da disfunção dos fatores da coagulação, a patogenia da diátese hemorrágica pode envolver outros fatores como alterações na permeabilidade, degeneração da musculatura lisa e de fibras elásticas dos vasos (Jones et al. 2000). Normalmente, a ingestão de grandes quantidades de dicumarol pode causar rápida vasodilatação, seguida de queda na pressão arterial, colapso circulatório e morte (Humphreys 1988). Os bovinos toleram dose única de até $50 \mathrm{mg} / \mathrm{kg}$ de peso vivo de warfarina, sem que qualquer sinal clínico seja evidenciado, porém se a mesma for ingerida por 10 dias seguidos, observa-se apenas leve prolongamento no tempo de coagulação. Os animais podem adoecer e perder o apetite quando doses de $200 \mathrm{mg} / \mathrm{kg} / \mathrm{dia}$ são administradas por mais de 12 dias (Humphreys 1988). Já de acordo com Radostits et al. (2000), 50\% dos animais podem morrer quando há ingestão desta mesma dose de warfarina durante 5 dias. A administração de pequenas doses não-letais de warfarina, entre 0,1 e $0,3 \mathrm{mg} / \mathrm{kg}$, em vacas gestantes pode ocasionar morte fetal e aborto ou morte de bezerros após 3 a 4 dias do nascimento, pela ruptura de vasos importantes (Pugh 1968, Humphreys 1988, Radostits et al. 2000).

\section{MATERIAL E MÉTODOS}

O surto ocorreu no período de 22 a 26 de março de 2004, no Setor de Reprodução do Instituto de Zootecnia/UFRRJ, município de Seropédica, Estado do Rio de Janeiro. Parte de um lote de 40 vacas Nelore e três touros Tabapuã adoeceu, dos quais duas vacas e um touro morreram e foram necropsiados. Coletaram-se fragmentos de diversos órgãos, os quais foram fixados em formalina a $10 \%$. O material destinado ao exame histopatológico foi processado pelos métodos de rotina, incluídos em parafina, cortados na espessura de $5 \mu$ e corados pela hematoxilina-eosina, nas dependências do Projeto Sanidade Animal (PSA) do convênio Embrapa/UFRRJ, Seropédica, RJ.

Amostras de feno e cevada que estavam sendo consumidos pelos animais que adoeceram foram coletadas diretamente do cocho, para a realização de análise química e cromatográfica. No momento da necropsia colheu-se conteúdo dos pré-estômagos de dois animais que morreram (Bovinos 1 e 3), além de fígado e rim do Bovino 3 . As amostras, enviadas ao Laboratório de Análises Toxicológicas Ltda Latox, Porto Alegre, RS, foram submetidas à análise química por cromatografia em camada delgada e cromatografia gasosa para identificação de derivados cumarínicos.

Para realização dos experimentos foram utilizados três bovinos (A, B e C), machos jovens, sem raça definida, pesando cerca de 250 $\mathrm{kg}$. Estes animais permaneceram no biotério do Projeto Sanidade Animal do convênio Embrapa/UFRRJ (PSA), no período de 26.3.04 a 13.4.04 e foram alimentados da seguinte forma: Bovino A recebeu exclusivamente feno de Tifton (Cynodon sp) proveniente do local do surto, Bovino B recebeu capim Napier picado (Pennisetum purpureum) e feno da grama Paspalum notatum, provenientes do PSA, e $4 \mathrm{~kg} / \mathrm{dia}$ de cevada provenientes do local do surto e Bovino C, utilizado como controle, recebeu apenas feno de $P$. notatum e capim Napier picado provenientes do PSA.

\section{RESULTADOS}

\section{Manifestações clínicas e achados anátomo e histopato- lógicos}

Os animais estavam bem até aproximadamente às 12 horas do dia 21.3.04; no dia seguinte, encontrou-se um animal morto (Bov. 1); constatou-se que parte de um lote de 40 fêmeas Nelore e três machos Tabapuã adoecera com quadros de severidade discreta a 

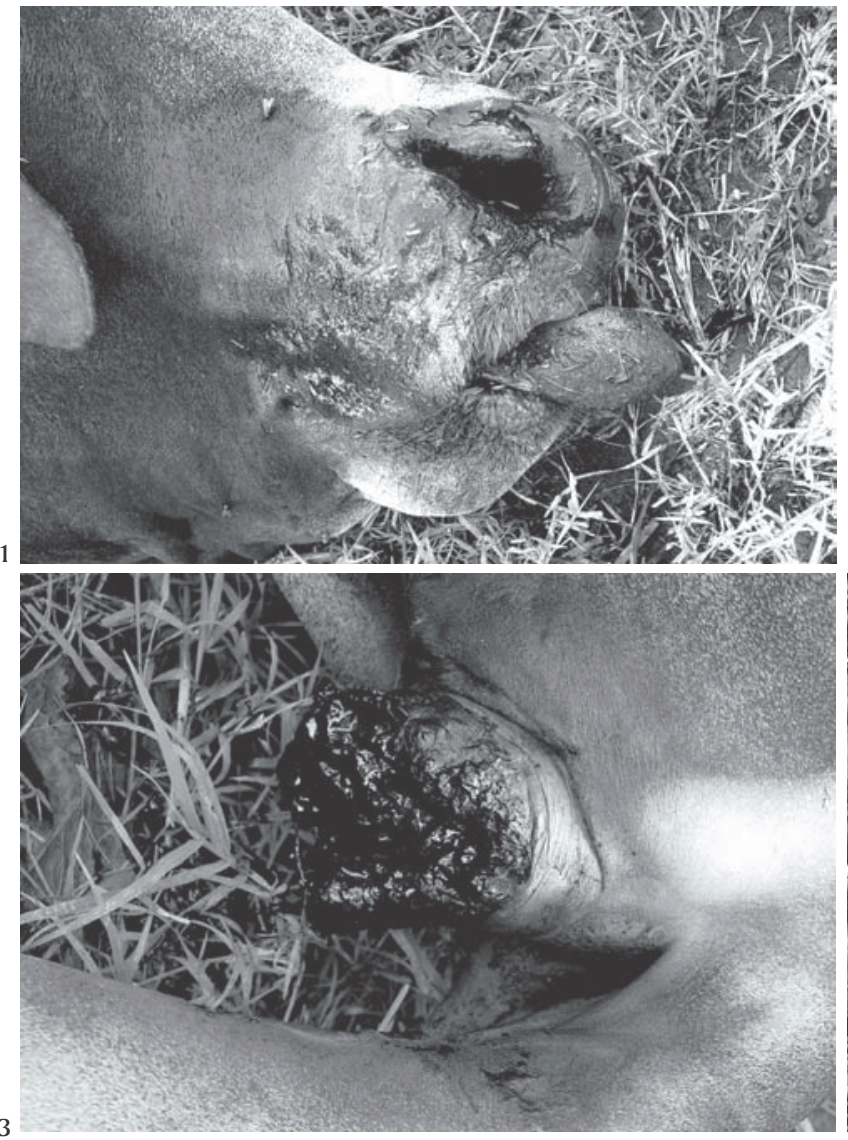

Fig. 1. Hemorragia nasal na intoxicação por derivado cumarínico (Bovino 3).

Fig. 3. Prolapso retal com extensa hemorragia (Bovino 3).

grave. Cinco animais estavam gravemente enfermos (três vacas Nelore, Bov. 2, 4 e 5, e dois touros Tabapuã, Bov. 3 e 6). Dois destes (Bov. 2 e 3) também foram encontrados mortos nos dias 23 e 26.3.04, respectivamente; os outros (Bov. 4,5 e 6 ) se recuperaram gradativamente. Outros animais do mesmo lote apresentavam apenas leve apatia e diminuição do apetite.

Nas visitas ao curral onde ocorreu o surto, foi obtida a informação de que a utilização de raticidas era feita com relativa frequiência no estabelecimento. Na sala de estocagem de medicamentos e alimentos encontrou-se uma caixa de raticida isca, à base de bromadiolone $\left(\mathrm{Maki}^{\circledR}\right)$. As principais alterações clínicas (Fig. 1 a 3) e os dados sobre as necropsias (Fig. 4 a 8) estão detalhados nos Quadros 1 e 2, respectivamente, e nos resumos dos protocolos.

Os exames histopatológicos revelaram alterações hemorrágicas correspondentes às encontradas na macroscopia.

Experimentação. Os experimentos realizados com feno e cevada, fornecidos ao rebanho enfermo, resultaram negativos e, ao final de 18 dias, foram encerrados, visto que os animais não apresentaram qualquer alteração clínica durante todo período.

Análises químicas. A pesquisa de derivados cumarínicos em conteúdos de rúmem, retículo, omaso e abomaso, em fígado

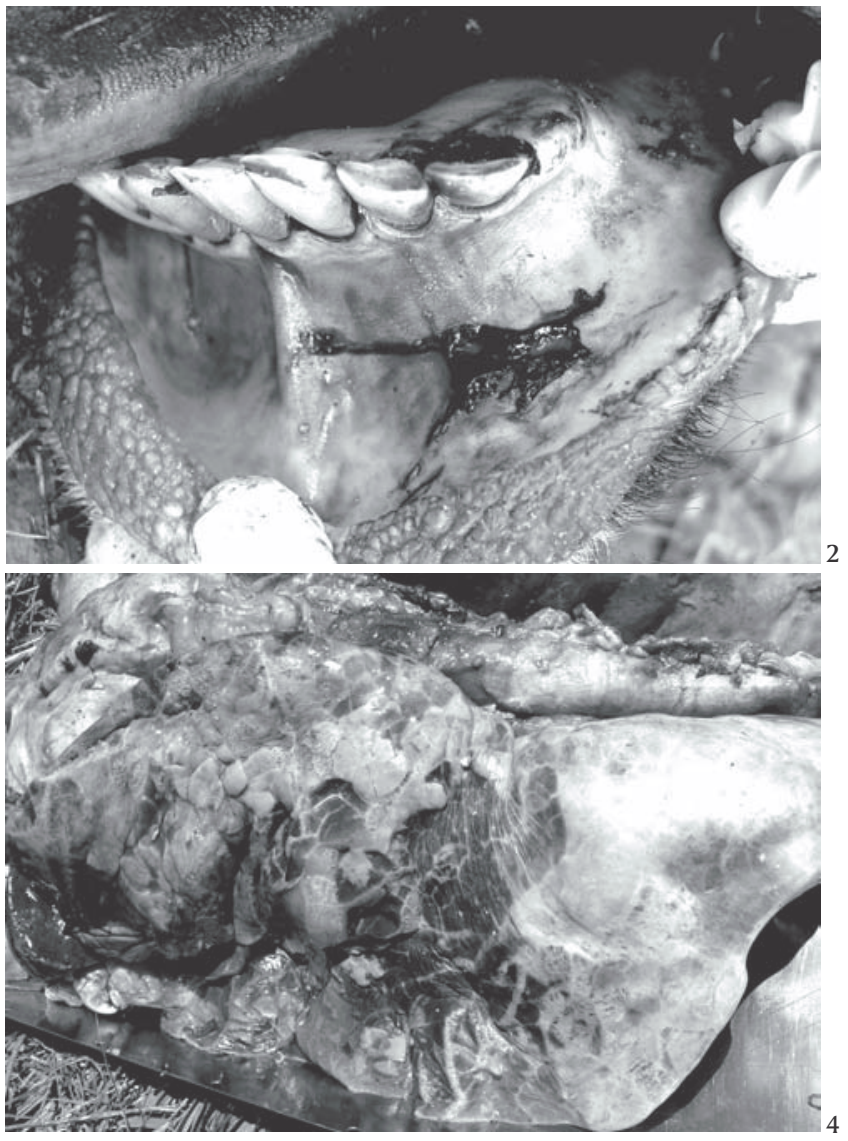

Fig. 2. Coágulos na superfície da gengiva (Bovino 3).

Fig. 4. Pulmão com áreas de atelectasia, hemorragia e enfisema (Bovino 1).

e rim, bem como na cevada resultaram positivas para o grupo químico das cumarinas (Quadro 3).

\section{Resumo dos protocolos}

Bovino 1. Macho, cerca de 8 anos, tabapuã. Na manhã de 22.3.04, aprox. às 7:00 horas, o animal foi encontrado morto. Estima-se que a evolução do quadro clínico-patológico tenha sido de no máximo 19 horas. Apesar do horário preciso da morte não ser conhecido, o animal foi visto aparentemente sadio no dia anterior às 12 horas. A necropsia foi realizada às 11:00 horas do dia 22.3.04, e de uma forma geral, $o$ animal estava em adiantado estado de autólise. Observaram-se apenas discretas alterações no fígado que apresentou-se amarelado, e o pulmão exibia aspecto "armado", "borrachudo" e "marmóreo", com acentuado enfisema alveolar e interlobular, áreas de atelectasia e hemorragias.

Bovino 2. Fêmea, cerca de 8 anos, Nelore. Em 22.3.04, o animal apresentava-se apático, anoréxico, com acentuada diarréia sanguinolenta e sialorréia. Durante o dia houve agravamento do quadro clínico e na manhã do dia seguinte (23.3.04) foi encontrado morto. A evolução do quadro clínico foi de aproximadamente 43-45 horas, supondo-se que este animal tenha adoecido logo após a última observação do rebanho em 21.3.04 às 12 horas. A necropsia foi realizada às 9:30 horas. Observaramse mucosas oculares levemente cianóticas e presença de muco na ampola retal. Tecido subcutâneo: equimoses na região do costado direito. Cavidade torácica: epiglote congesta. Traquéia com edema de mucosa e, no lúmen, secreção mucosa e espuma. Pulmão com enfisema subpleural e interlobular, parênquima difusamente avermelhado e com 

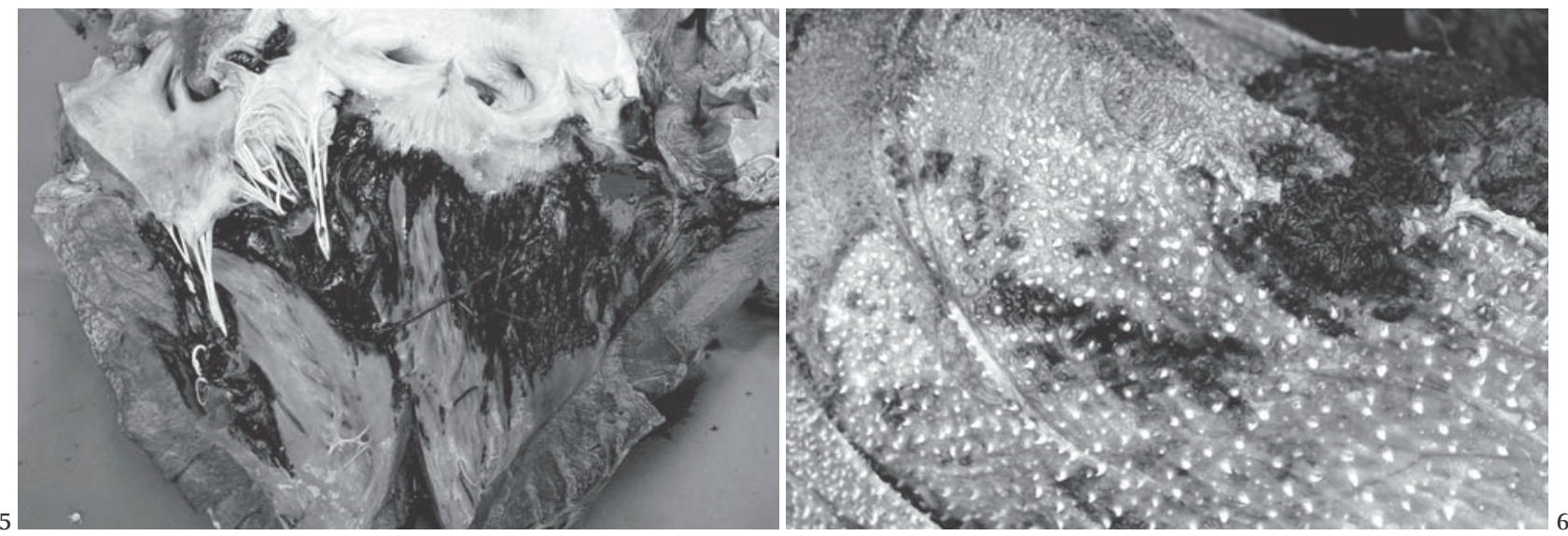

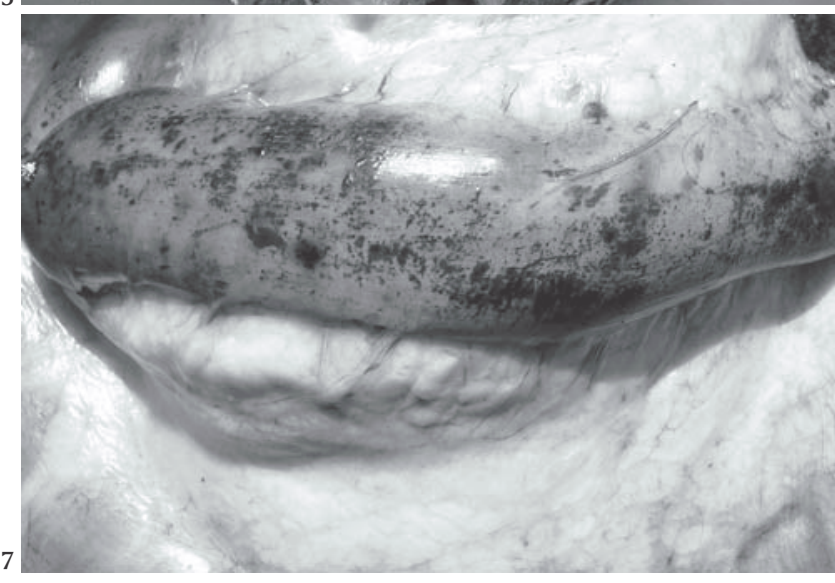

Fig. 5. Extensas hemorragias no endocárdio, na intoxicação por derivado cumarínico (Bovino 3).

Fig. 7. Petéquias e equimoses na serosa do intestino grosso (Bovino 3).

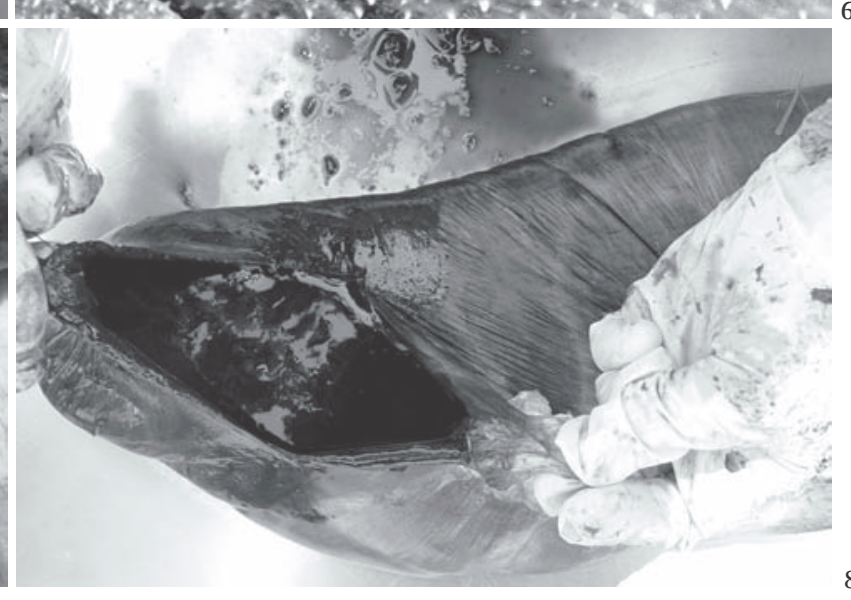

Fig. 6. Hemorragias na mucosa do omaso (Bovino 3).

Fig. 8. Intestino grosso repleto de conteúdo liquido hemorrágico (Bovino 3).

\section{Quadro 1. Principais alterações clínicas, evolução e desfecho, no envenenamento de bovinos por derivado cumarínico}

\begin{tabular}{|c|c|c|c|c|c|c|}
\hline Quadro clínico & Bovino 1 & 1 Bovino 2 & 2 Bovino 3 & Bovino 4 & Bovino 5 & Bovino 6 \\
\hline Apatia & -a & +++ & +++ & +++ & +++ & +++ \\
\hline Sialorréia & - & +++ & +++ & ++ & ++ & ++ \\
\hline Anorexia & - & +++ & +++ & +++ & +++ & +++ \\
\hline Diarréia aquosa e/ou sanguinolenta & - & +++ & +++ & +++ & +++ & - \\
\hline Redução dos movimentos ruminais & - & - & +++ & - & - & +++ \\
\hline Coágulos na cavidade oral e ânus & - & - & ++ & - & - & - \\
\hline Decúbito esterno-abdominal & - & - & +++ & - & - & ++ \\
\hline Cabeça voltada para o flanco & - & - & ++ & - & - & ++ \\
\hline Instabilidade ao levantar e caminhar & - & - & +++ & - & - & - \\
\hline Incoordenação & - & - & +++ & + & + & + \\
\hline Respiracão superficial, de baixa amplitude e predominantemente abdomin & inal - & - & ++ & - & - & - \\
\hline Exsudato catarral/sanguinolento nasal bilateral & - & - & +++ & - & - & - \\
\hline Evolução (estimada em horas) & 19 & 43 & 116 & 71 & 71 & 57 \\
\hline Desfecho & Morreu & Morreu & Morreu & Recuperou-se & Recuperou-se & Recuperou-se \\
\hline
\end{tabular}

a Sinais clínicos +++ acentuados, ++ moderados, + leves, - ausentes; n/t não testado.

áreas de hemorragias difusas. Coração com petéquias e equimoses no epicárdio, principalmente na base; equimoses no endocárdio. Cavidade abdominal: rúmen com hemorragias na serosa e base das papilas que, após a raspagem da superfície queratinizada, observou-se hiperemia da mucosa. Retículo com grandes áreas hiperêmicas. Omaso aumentado de volume e com conteúdo ressecado, congestão e equimoses das folhas.
Vasos mesentéricos congestos. Intestinos edemaciados, repleto de muco e com áreas irregulares avermelhadas. Fígado de coloração levemente escurecida e vesícula biliar repleta, com parede edemaciada e serosa com áreas hemorrágicas. Baço com superfície irregular de aspecto rugoso e petéquias e sufusões difusas. Rins apresentando a região medular mais congesta e rim direito com áreas irregulares e avermelhadas na 
Quadro 2. Achados macroscópicos no envenenamento de bovinos por derivado cumarínico

\begin{tabular}{|c|c|c|c|}
\hline & Bovino 1 (SAP 30103) & Bovino 2 (SAP 30104) & Bovino 3 (SAP 30106) \\
\hline Identificação & Tabapuã, macho, aprox. 8 anos & Nelore, fêmea, aprox. 8 anos & Tabapuã, macho, aprox. 8 anos \\
\hline Data/hora da morte & Amanheceu morto no dia 22.3 .04 & Amanheceu morto no dia 23.3.04 & Amanheceu morto no dia 26.3.04 \\
\hline Exame externo & $\mathrm{s} / \mathrm{a}^{\mathrm{a}}$ & Mucosas oculares cianóticas + & $\begin{array}{l}\text { Coágulos na boca e esfíncter anal, narinas } \\
\text { com muco e sangue }\end{array}$ \\
\hline Tecido subcutâneo & $\mathrm{s} / \mathrm{a}$ & Equimoses na região do costado direito & Equimoses e sufusões difusas ++ \\
\hline Baço & s/a & $\begin{array}{l}\text { Superfície irregular de aspecto rugoso; } \\
\text { petéquias e sufusões difusas }\end{array}$ & Equimoses subcapsulares ++ \\
\hline Omento & s/a & Vasos mesentéricos congestos & s/a \\
\hline Fígado & Amarelado & $\begin{array}{l}\text { Congestão +; vesícula biliar repleta, parede } \\
\text { edemaciada e serosa com equimoses }\end{array}$ & Vesícula biliar com edema e sufusões \\
\hline Rúmem & $\mathrm{s} / \mathrm{a}$ & $\begin{array}{l}\text { Hemorragias na serosa e base das papilas, } \\
\text { mucosa hiperêmica }\end{array}$ & $\mathrm{s} / \mathrm{a}$ \\
\hline Retículo & $\mathrm{s} / \mathrm{a}$ & Grandes áreas hiperêmicas & s/a \\
\hline Omaso & $\mathrm{s} / \mathrm{a}$ & $\begin{array}{l}\text { Aumentado de volume, conteúdo ressecado, } \\
\text { congestão e equimoses das folhas }\end{array}$ & $\begin{array}{l}\text { Aumentado de volume e firme, folhas com } \\
\text { numerosas equimoses subepiteliais e } \\
\text { equimoses + na serosa }\end{array}$ \\
\hline Abomaso & $\mathrm{s} / \mathrm{a}$ & s/a & Víbices subserosas e petéquias na mucosa \\
\hline Intestinos & $\mathrm{s} / \mathrm{a}$ & $\begin{array}{l}\text { Repleto de muco, com áreas irregulares } \\
\text { avermelhadas e parede edemaciada }\end{array}$ & $\begin{array}{l}\text { Petéquias e equimoses na serosa intestinal } \\
+++ \text {, conteúdo líquido sanguinolento }+++\end{array}$ \\
\hline $\operatorname{Rim}$ & $\mathrm{s} / \mathrm{a}$ & $\begin{array}{l}\text { Esquerdo: medular congesta; Direito: áreas } \\
\text { irregulares e avermelhadas na cortical }\end{array}$ & Equimoses no tecido perirrenal + \\
\hline Bexiga & s/a & Edema e petéquias & s/a \\
\hline Trato genital & $\mathrm{s} / \mathrm{a}$ & $\begin{array}{l}\text { Cornos uterinos difusamente avermelhados; } \\
\text { conteúdo mucoso }+\end{array}$ & $\mathrm{s} / \mathrm{a}$ \\
\hline Laringe e faringe & $\mathrm{s} / \mathrm{a}$ & $\mathrm{s} / \mathrm{a}$ & Equimoses, hematomas perilaríngeos \\
\hline Traquéia & $\mathrm{s} / \mathrm{a}$ & Equimoses na parede e espuma avermelhada & Equimoses na parede e espuma avermelhada \\
\hline Tireóide & $\mathrm{s} / \mathrm{a}$ & $\mathrm{s} / \mathrm{a}$ & Difusamente hemorrágica +++ \\
\hline Pulmão & $\begin{array}{l}\text { Enfisema alveolar e interlobular, } \\
\text { aspecto "armado", "borrachudo", } \\
\text { "marmóreo"; com áreas de atelec- } \\
\text { tasia e hemorragias }\end{array}$ & $\begin{array}{l}\text { Enfisema subpleural e interlobular, parênqui- } \\
\text { ma difusamente avermelhado com áreas de } \\
\text { hemorragias }\end{array}$ & $\begin{array}{l}\text {-Difusamente avermelhado e de aspecto } \\
\text { enfisematoso }\end{array}$ \\
\hline Coração & $\mathrm{s} / \mathrm{a}$ & $\begin{array}{l}\text { Petéquias e equimoses no epicárdio, princi- } \\
\text { palmente na base }+++ \text {; equimoses no en- } \\
\text { docárdio }+++\end{array}$ & $\begin{array}{l}\text { Líquido sanguinolento no saco pericárdico; } \\
\text { pericárdio e epicárdio com petéquias e equi- } \\
\text { moses }+++ \text {; endocárdio com equimoses e } \\
\text { sufusões mais acentuadas no ventrículo es- } \\
\text { querdo }+++ \text {. }\end{array}$ \\
\hline Músculos & $\mathrm{s} / \mathrm{a}$ & Intercostais com equimoses + & Equimoses nos intercostais e glúteos + \\
\hline
\end{tabular}

a + Lesão leve, ++ moderada, +++ acentuada, s/a sem alteração.

Quadro 3. Resultados de análises por métodos de cromatografia em camada delgada, cromatografia gasosa e análise química para pesquisa de derivados cumarínicos

\begin{tabular}{lccc}
\hline Material analisado & Bovino 1 & Bovino 2 & Bovino 3 \\
\hline Conteúdo do rúmem & $+^{\mathrm{a}}$ & $\mathrm{NP}$ & + \\
Conteúdo do retículo & + & $\mathrm{NP}$ & + \\
Conteúdo do omaso & + & $\mathrm{NP}$ & + \\
Conteúdo do abomaso & + & $\mathrm{NP}$ & + \\
Figado & $\mathrm{NP}$ & $\mathrm{NP}$ & + \\
Rim & $\mathrm{NP}$ & $\mathrm{NP}$ & + \\
Cevadac & + & + & + \\
Feno & - & - & - \\
\hline a + positivo, - negativo. & - & & \\
b NP não pesquisado. & & & \\
${ }^{\mathrm{c}}$ Alimentos coletados diretamente do cocho onde os animais que \\
adoeceram estavam se alimentando.
\end{tabular}

cortical. Bexiga edemaciada e com petéquias. Cornos uterinos difusamente avermelhados e com pequena quantidade de conteúdo mucoso.

Bovino 3. Macho, cerca de 8 anos, Tabapuã. Em 22.3.04 verificaram-se apatia, anorexia, fezes pastosas e sanguinolentas, lacrimejamento bilateral e exsudato catarral nasal bilateral, mucosas levemente hipocoradas, temperatura de $38,2^{\circ} \mathrm{C}, 49$ batimentos cardíacos por minuto e respiração de baixa amplitude, superficial, predominantemente abdominal, com frequiência de 20 movimentos respiratórios por minuto. Havia dificuldade na auscultação do campo cardíaco e apenas um foco de crepitação no campo pulmonar foi evidenciado, com silêncio em praticamente todo o restante do campo. Observaram-se ainda acentuada incoordenação, dificuldade de se manter em estação e se locomover, instabilidade ao levantar e caminhar. No dia seguinte (23.3.04) continuava apático, sempre em decúbito esternal, levantando-se apenas quando estimulado, com andar cambaleante, voltava ao decúbito logo em seguida. Em 24.3.04, apresentou sinais de agravamento como anúria, permaneceu apático, decúbito em grande parte do tempo e observaram-se estrias de sangue nas fezes e no corrimento nasal muco-purulento. $\mathrm{O}$ tratamento administrado desde o primeiro dia em que adoeceu (Flotril, Mercepton e soro glicosado) não surtiu efeito. Em 25.3.04 observaram-se 
ausência de reflexo ocular, infusórios ruminais quase todos mortos e pro va do azul de metileno retardada (mais de 6 minutos) SIC. Amanheceu morto no dia 26.3.04. A evolução do quadro clínico foi de aprox. de 4 dias e 20 horas. No dia 26.3.04 foi necropsiado às 10:00 horas. Observaram-se coágulos na boca, muco e sangue bilateral nas narinas e muitos coágulos aderidos ao esfíncter anal. O tecido subcutâneo apresentava equimoses e sufusões difusas em quantidades moderadas. Equimoses foram observadas na parede da laringe, faringe e epiglote. Tireóides com extensas hemorragias. Cavidade torácica: traquéia com equimoses na parede e espuma avermelhada. Pulmão difusamente avermelhado e enfisematoso. No coração havia líquido sanguinolento no saco pericárdico; pericárdio com petéquias e equimoses; endocárdio com equimoses e sufusões mais extensas no ventrículo esquerdo, próximo às válvulas. Cavidade abdominal: o omaso apresentava-se aumentado de volume e firme, com numerosas equimoses subepiteliais nas folhas e poucas hemorragias na parede; abomaso com hemorragias subserosas em forma de estrias e petéquias na mucosa. Na serosa intestinal havia numerosas petéquias e equimoses e grande quantidade de conteúdo líquido sanguinolento (muitos litros). Fígado levemente mais friável e serosa da vesícula biliar com edema e difusamente hemorrágica. Baço com moderada quantidade de equimoses na cápsula. Tecido perirrenal com petéquias.

Bovinos 4 e 5. Fêmeas, adultas, Nelore. Os primeiros sinais clínicos foram observados na manhã de 22.3.04 e consistiram em anorexia, apatia sialorréia moderada, diarréia aquosa, de coloração escura e com estrias de sangue e discreta incoordenação. No dia seguinte (23.3.04) ainda apresentavam-se apáticas e anoréxicas, com diarréia profusa, sanguinolenta e com grande quantidade de muco. Recuperaram-se gradativamente e em 25.3.04 apresentavam-se normais. Estima-se um período de evolução de 71 horas.

Bovino 6. Macho, adulto, Tabapuã. As primeiras manifestações clínicas caracterizaram-se por apatia, anorexia, diarréia sanguinolenta, sialorréia, permanência em decúbito esternal com a cabeça voltada para o flanco, leve incoordenação e ausência de movimentos ruminais. Pode-se notar discreta melhora do quadro clínico a partir de 23.3 .04 e no dia seguinte o animal apresentava-se aparentemente normal. A evolução clínica foi de aproximadamente 57 horas, desde 22.3.04, quando os primeiro sinais foram evidenciados até a completa recuperação em 24.3.04.

\section{DISCUSSÃO}

O diagnóstico de intoxicação por derivados cumarínicos, neste caso, baseou-se nos achados clínico-patológicos e, principalmente, na análise toxicológica que revelou a presença de derivado cumarínico no conteúdo gastrintestinal de dois dos animais mortos (Bovs 1 e 3), no fígado e rim de um deles (Bov.3), bem como na cevada que era ingerida pelos animais por ocasião do surto. Apenas nas amostras de fígado e rim do Bov. 3, estas substâncias foram detectadas em quantidades próximas do limite de detecção do método analítico, ou seja, em nível de traços, o que possivelmente ocorreu devido ao envio de quantidades insuficientes. As análises preliminares do feno não evidenciaram a presença de derivados cumarínicos, porém a detecção destas substâncias em apenas um único tecido é suficiente e constitui um importante achado para o diagnóstico.

É provável que o produto tenha sido colocado sobre ou em meio aos alimentos no cocho, pois que os animais que não estavam se alimentando no mesmo local, não adoeceram. Essa hipótese é reforçada pelo fato de que nenhuma alteração clínica foi observada durante os experimentos realizados através da administração do feno e da silagem, que eram fornecidos aos outros animais por ocasião da ocorrência do surto. Desta forma, tudo indica que esse episódio esteja associado à adição acidental ou intencional de derivado cumarínico, e que os animais o ingeri- ram em quantidades variadas, visto que apresentaram diferentes períodos de evolução e graus de sintomas e morte de três animais.

Bovinos jovens são mais susceptíveis ao dicumarol, provavelmente em função das baixas reservas de vitamina K; recémnascidos podem sangrar até morrer enquanto que suas mães não apresentam sinais clínicos e exibem apenas tempo de sangramento prolongado (Valli \& Parry 1993). Depressão e anorexia ocorrem em todas as espécies antes das manifestações hemorrágicas (Aiello 1998); esses sinais foram os únicos observados em alguns animais do rebanho afetado e que posteriormente se recuperaram. Outros sinais são dependentes da severidade das hemorragias e refletem fraqueza, decúbito, dispnéia moderada, palidez de mucosas (Aiello 1998, Radostits et al. 2000), ataxia e cólica (Aiello 1998). Também podem ser observadas epistaxe, diarréia sanguinolenta (Humphreys 1988) ou melena, hematúria (Humphreys 1988, Valli \& Parry 1993, Aiello 1998), hifema, hemoptise, hematomas e hemorragias em mucosas (Valli \& Parry 1993, Radostits et al. 2000), quase todos observados nos animais deste surto que tiveram um quadro grave ou que morreram.

No Brasil existem algumas doenças em bovinos que cursam com diátese hemorrágica e que devem ser consideradas como importantes no diagnóstico diferencial da intoxicação por cumarínicos. Existe grande semelhança entre a diátese hemorrágica induzida pela ingestão de Pteridium aquilinum com aquela verificada na intoxicação por cumarínicos, porém a epidemiologia e a histopatologia na intoxicação por P. aquilinum são características, bem como a presença da planta na pastagem, especialmente da brotação e a acentuada rarefação do tecido hematopoético, com trombocitopenia e aumento no tempo de coagulação (Tokarnia et al. 2000). As anormalidades na coagulabilidade do sangue podem ser secundárias a outros distúrbios adquiridos, como hepatopatias severas, com perda significativa da capacidade de síntese dos fatores da coagulação e, conseqüente tendência hemorrágica (Valli \& Parry 1993, Cotran et al. 2000), porém, há algumas diferenças nas manifestações clínicas nestes distúrbios. A intoxicação por plantas hepatotóxicas como Cestrum laevigatum, podem levar a hemorragias, mas são bem mais discretas quando comparadas com o envenenamento cumarínico. Além disso, a observação da planta no pasto, associada às condições favoráveis ao seu consumo e o clássico aspecto de "noz-moscada" no fígado, bem como as manifestações clínicas de encefalopatia hepática (Tokarnia et al. 2000) nos permitem diferenciar tal condição da intoxicação por derivados cumarínicos.

Agradecimentos.- Aos professores José Eugênio Trés, Vera Lúcia Teixeira de Jesus e Nelson Jorge de Matos, do Instituto de Zootecnia da UFRRJ, pela cessão dos animais e apoio à realização dos exames toxicológicos.

\section{REFERÊNCIAS}

Aiello S.E. 1998. Rodenticide poisoning, p.2142-2143. In: The Merck Veterinary Manual. 8th ed. Merck \& Co., New Jersey, USA.

Ashworth B. 1973. Frequency of animal poisoning by warfarin. Vet. Rec. 93(2):50.

Cope R.B. 2004. Small animal anticoagulant rodenticide poisoning. Aust. Vet. Pract. 34(2):50. 
Cotran R.S., Kumar V. \& Collins T. 2000. Doença dos eritrócitos e distúrbios hemorrágicos, p.540-579. Robin's Patologia Estrutural e Funcional. $6^{a}$ ed. Guanabara Koogan, Rio de Janeiro.

Fox F.H. \& Rebhun W.C. 1983. Warfarin poisoning with complications in heifer. Vet. Med. Small Anim. Clin. 78(10):1611-1613.

Jones T.C., Hunt R.D. \& King N.W. 2000. Patologia Veterinária. 6 a $^{\text {ed }}$. Manole, São Paulo, p.744-745.

Gripper J. 1973. Frequency of animal poisoning by warfarin. Vet. Rec. 93(5): 148 .

Humphreys D.J. 1988. Veterinary Toxicology. 3rd ed. Baillière Tindall, London, p.129-183.

Lehninger A.L. 1984. Princípios de Bioquímica. Vitaminas e Microelementos na Função de Enzimas. Sarvier, São Paulo, p.198-199.

Lutze G., Romhild W., Elwert J., Leppelt J. \& Kutschmann K. 2003. Case report - Phenprocoumon (Marcumar ${ }^{\circledR}$, Falithrom ${ }^{\circledR}$ ) as an unusual reason for coumarin poisoning in a dog. Dtsch. Tierärztl. Wochenschr. 110(1):3133.
Pugh D.M. 1968. Abortifacient action of warfarin in cattle. Brit. J. Pharm. 33(1):210

Puschner B., Galey F.D., Holstege D.M. \& Palazoglu M. 1998. Sweet clover poisoning in dairy cattle in California. J. Am. Vet. Med. Assoc. 212(6):857859

Radostits D.M, Gay C.C., Blood, D.C. \& Hinchcliff, K. W. 2000. Veterinary Medicine. 9th ed. W.B. Saunders, London.

Runciman D.J., Lee A.M., Reed K.F.M. \& Walsh J.R. 2002. Dicoumarol toxicity in cattle associated with ingestion of silage containing sweet vernal grass (Anthoxanthum odoratum). Aust. Vet. J. 80(1-2):28-32.

Stirling Y. 1995. Warfarin-induced changes in procoagulant and anticoagulant proteins. Blood Coagulation Fibrinolysis 6(5):361-373.

Tokarnia C.H., Döbereiner J. \& Peixoto P. 2000. Plantas Tóxicas do Brasil. Editora Helianthus, Rio de Janeiro. 310p.

Valli V.E.O. \& Parry B.W. 1993. Hematopoietic system, p.264. In: Jubb K.V.F., Kennedy P.C. \& Palmer N. (ed.) Pathology of Domestic Animals. Vol. 2. 4th ed. Academic Press, San Diego. 